This is the final peer-reviewed accepted manuscript of:

J.F. Raymundo Junior, R. De Cesaro Oliveski, L.A.O. Rocha, C. Biserni

"Numerical investigation on phase change materials (PCM): The melting process of erythritol in spheres under different thermal conditions"

In: International Journal of Mechanical Sciences, Volume 148, 2018, Pages 20-30

The final published version is available online at:

https://doi.org/10.1016/i.ijmecsci.2018.08.006

Rights / License:

The terms and conditions for the reuse of this version of the manuscript are specified in the publishing policy. For all terms of use and more information see the publisher's website.

This item was downloaded from IRIS Università di Bologna (https://cris.unibo.it/)

When citing, please refer to the published version. 


\title{
NUMERICAL INVESTIGATION ON PHASE CHANGE MATERIALS (PCM): THE MELTING PROCESS OF ERYTHRITOL IN SPHERES UNDER DIFFERENT THERMAL CONDITIONS
}

\author{
J. F. Raymundo Junior ${ }^{1}$, R. De Cesaro Oliveski ${ }^{1}$, L.A.O. Rocha ${ }^{1}$ and C. Biserni ${ }^{2}$ \\ ${ }^{1}$ Mechanical Engineering Graduate Program, Universidade do Vale do Rio dos Sinos, \\ 93022-750 São Leopoldo, Brazil. \\ ${ }^{2}$ Dipartimento di Ingegneria Industriale, Alma mater Studiorum Università di Bologna, \\ Viale Risorgimento 2, 40136 Bologna, Italy.
}

\begin{abstract}
In this paper, a numerical study on the melting process of the PCM erythritol in 12,7 mm diameter spheres subjected to external flow has been carried out. This configuration is analyzed varying the temperature difference between the PCM melting point and the external flow, the Reynolds number as well as the sphere position in the array. The problem is considered two-dimensional in geometry and transient in time. The numerical model here developed consists of the continuity, momentum and energy equations. The results have been initially validated using numerical and experimental data from literature. Afterwards, results of liquid fraction, heat flux and total melting time have been proposed and illustrated. Based on pure observation, a slight difference in the phase change phenomena when comparing different sphere positions in the array has emerged. These phenomena proved to be much more influenced by the external flow temperature and by the Reynolds number. In all cases, at $30 \%$ of the total melting time, $50 \%$ of the total energy had been absorbed by the PCM. The liquid PCM layer above the solid has a great influence on the heat flux, precisely the more extensive the PCM layer, the lower the heat exchange. The local heat flux value decreases significantly in regions in contact with air and liquid PCM. Contrarily, at the sphere base, where there is solid PCM during the whole process, the local heat flux value is almost constant during the whole melting. Finally, significant differences have emerged when comparing the results referred to the hypothesis here contemplated of uniform heat transfer coefficient and local heat transfer coefficient function of the sphere angle.
\end{abstract}

Keywords: Thermal storage. Phase change materials (PCM). Pebble bed heat storage. Computational fluid dynamics. 


\section{Nomenclature}

C "mushy zone" constant $\left[\mathrm{kg} \mathrm{m}^{-2} \mathrm{~s}^{-2}\right]$

$\mathrm{C}_{\mathrm{p}} \quad$ specific heat at constant pressure $\left[\mathrm{J} \mathrm{kg}^{-1} \mathrm{~K}^{-1}\right]$

D diameter $[\mathrm{m}]$

$\vec{g} \quad$ gravity acceleration $\left[\mathrm{m} \mathrm{s}^{-2}\right]$

h local heat transfer coefficient $\left[\mathrm{W} \mathrm{m}^{-2} \mathrm{~K}^{-1}\right]$

$\overline{\mathrm{h}}$ mean heat transfer coefficient $\left[\mathrm{W} \mathrm{m} \mathrm{m}^{-2} \mathrm{~K}^{-1}\right]$

$\mathrm{H}$ height $[\mathrm{m}]$

$\mathrm{k}$ thermal conductivity $\left[\mathrm{W} \mathrm{m} \mathrm{m}^{-1} \mathrm{~K}^{-1}\right]$

$\mathrm{L} \quad$ latent heat $\left[\mathrm{J} \mathrm{kg}^{-1}\right]$

$\mathrm{p} \quad$ pressure $[\mathrm{Pa}]$

q" heat flux $\left[\mathrm{W} \mathrm{m}^{-2}\right]$

Q Thermal energy

$\mathrm{S}$ momentum equation source term $\left[\mathrm{Pa} \mathrm{m}^{-1}\right]$

t time $[\mathrm{s}]$

$\mathrm{T} \quad$ temperature $[\mathrm{K}]$

$\mathrm{T}_{\infty} \quad$ free stream temperature $[\mathrm{K}]$

$\vec{V} \quad$ velocity vector $\left[\mathrm{m} \mathrm{s}^{-1}\right]$

$\overrightarrow{V_{p}} \quad$ pull velocity $\left[\mathrm{m} \mathrm{s}^{-1}\right]$

$\mathrm{X}, \mathrm{Y}, \mathrm{Z}$ spatial coordinates [m]

\section{Greek symbols}

$\alpha \quad$ liquid fraction

$\beta \quad$ volume fraction

$\Delta \quad$ difference

$\nabla \quad$ differential operator

$\varepsilon \quad$ numerical constant $(0.001)$

$\lambda \quad$ enthalpy $\left[\mathrm{J} \mathrm{kg}^{-1}\right]$

$\mu \quad$ dynamic viscosity $\left[\mathrm{kg} \mathrm{m}^{-1} \mathrm{~s}^{-1}\right]$

$\rho \quad$ density $\left[\mathrm{kg} \mathrm{m}^{-3}\right]$ 
$\theta \quad$ angle between $\mathrm{Y}$ and $\mathrm{Z}$-axis

$\varphi \quad$ angle between $\mathrm{Z}$ and $\mathrm{X}$-axis

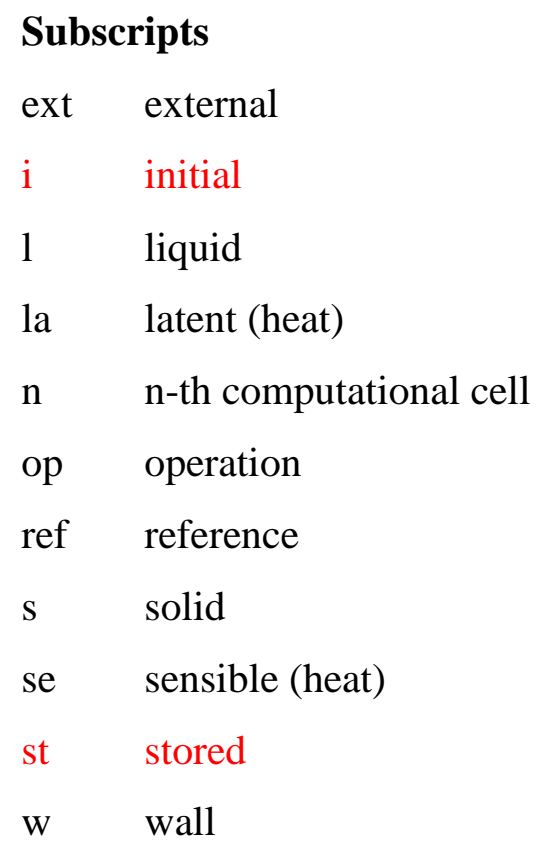

\section{INTRODUCTION}

The high thermal energy storage capacity associated with processes that use phase change materials (PCM) is of great interest in many engineering areas. Ref. [1] deals with the melting of nanoparticles-enhanced phase-change materials (NEPCM) in a square cavity by means of the finite element method. The impacts of the nanoparticles volume fraction and various models parameters on the melting behavior have been traced with time. Bondareva and Sheremet in Ref. [2] investigated the problem of complex interaction of natural convection and melting of phase change material inside a square cavity with a local heater of volumetric heat generation. Different geometric, thermal and fluid dynamic configurations are used to further enhance the performance of PCM systems. Due to their great applicability, spherical geometries have been extensively investigated, mainly in pebble bed thermal storage units, as reported in Refs. [3-7]. In this type of thermal storage unit, spheres filled with PCM are deposited inside a tank in which the fluid bathes the spheres, establishing various heat transfer processes that occur 
simultaneously [8]. The topic of PCM melting have been widely treated in literature both experimentally [9-13] and numerically [14-21].

The mathematical and numerical modelling of pebble bed thermal storage units present many factors that make their study a challenge. There are non-linear characteristics common to all phase change problems, together with the liquid phase natural convection, volumetric variation, solid phase movement, interaction between the PCM and air inside the spheres and the mixed convection of the fluid outside the spheres. All these characteristics increase the modelling and convergence difficulty as well as computational costs. Thus, it is common to simplify or to omit some of these phenomena in the numerical treatment, as illustrated in Ref. [17]. One of these modalities to simplify is to consider a constant heat flux [19] or constant temperature $[14,15,16,17,22]$ as prescribed thermal condition on the sphere wall. These assumptions are quite basic, since, usually, there is a fluid in contact the outside wall, transferring heat by convection so that the wall temperature is not uniform [23]. Fomin and Saitoh in Ref. [24] discovered a considerable discrepancy between the results referred to isothermal and non-isothermal conditions. Similarly, Assis et al. [17] and Archibold et al. [15] observed the same variance, attributing divergences in melting time between the numerical and physical models to the fact that the external convection was not contemplated in their treatments. Convection processes external to the sphere as well as heat conduction on the sphere wall have been considered in Ref. [23]; at the same time it is worth to mention that the solid PCM downward movement and the liquid PCM volumetric expansion have ben neglected. Progress in these topics and subtopics can also be found in Refs. [25-27].

The present work shows results of the melting process in pebble bed heat storage units with spheres containing PCM. The developed numerical model takes into account all the following phenomena (partially contemplated in previous literature): external heat convection, heat conduction on the metallic wall, liquid phase convection and volumetric expansion, as well as the solid phase downward movement. Three different Reynolds number and temperature differences between the PCM melting temperature and the external flow temperature have been considered for the external flow. Furthermore, the comparison of the results between three different spheres positions in the array have been investigated. 


\section{PEBBLE BED STORAGE UNITS: PHYSICAL MODEL}

A representation of the studied pebble bed thermal storage unit is shown in Fig. 1, where it is also possible to identify the spheres arrangement and the heat transfer and fluid flow direction. In this case, the spheres are subjected to the heat transfer process with external flow particularities. These particularities cause the external heat transfer coefficient $\left(\mathrm{h}_{\mathrm{ext}}\right)$ to vary in function of the relative position among the spheres, the flow angle of incidence and the thermal and fluid dynamics conditions, as illustrated in Ref. [28]. This configuration leads to a non-uniform heat transfer rate, as shown by Kao et al. in Ref. [29], for instance. In Fig. 1(b) the relation between the angles for different spheres is depicted, where $\theta$ represents the angle between the $\mathrm{Y}$ and $\mathrm{Z}$ axis and $\varphi$ represents the angle between the $\mathrm{Z}$ and $\mathrm{X}$ axis.

It is worth to mention that Kao et al. [29] analyzed flows with $\operatorname{Re}=1.0 \times 10^{4}$, $2.0 \times 10^{4}$ and $2.6 \times 10^{4}$. Figure 2(a) highlights the scheme used in these authors experiment, showing which spheres were studied. Values of $h_{\text {ext }}$ are defined as a function of $\theta$ and correspond to the mean value of $h_{\text {ext }}$ for each $\varphi$. It is noticeable that when $\mathrm{P}$ is at the top of the sphere, $\theta$ is equal to $0^{\circ}$ and equal to $180^{\circ}$ at the bottom. Figure 2(b) shows in details how $h_{\text {ext }}$ varies in function of $\theta$ for $\operatorname{Re}=1 \times 10^{4}$ and $2.6 \times 10^{4}$, for each of the three positions studied by the authors. It can be observed that the value of $h_{\text {ext }}$ is maximum at the top of the sphere and decreases up to, approximately, $125^{\circ}$ and then increases gradually. This behavior happens in all spheres, with changes in the minimum and maximum values, as well as the gradients.

The geometry studied in this paper, reproposed in Fig. 3, is spherical, with internal diameter (D) equal to $12.7 \mathrm{~mm}$. It is closed (not open to the atmosphere) and filled with PCM up to $85 \%$ of its height $(\mathrm{H})$. This means that $94 \%$ of its volume is filled with PCM and the remaining volume is filled with air. The wall is made of aluminum with a thickness of $2 \mathrm{~mm}$. Externally, hot air flows over the sphere, causing the PCM inside to change its phase. The PCM used is erythritol. It has a melting temperature of $391 \mathrm{~K}$, which allows its use in industrial processes, with medium/high temperatures, such as vapor systems and combustion gases. Erythritol physical properties, shown in Table 1, were obtained from the works of Agyenim et al. [30], Hesaraki [31] and Sillik and Gregson [32]. 
Table 1 - Erythritol physical properties

\begin{tabular}{lc}
\hline \multicolumn{1}{c}{ Property } & Value \\
\hline \hline Melting latent heat $\left(\mathrm{J} \mathrm{kg}^{-1}\right)$ & 339.800 \\
\hline Density $\left(\mathrm{kg} \mathrm{m}^{-3}\right)$ & $1480(389 \mathrm{~K}) ; 1300(413 \mathrm{~K})$ \\
\hline Specific heat $\left(\mathrm{J} \mathrm{kg}^{-1} \mathrm{~K}^{-1}\right)$ & $1350(389 \mathrm{~K}) ; 2740(413 \mathrm{~K})$ \\
\hline Thermal conductivity $\left(\mathrm{W} \mathrm{m}^{-1} \mathrm{~K}^{-1}\right)$ & $0.733(389 \mathrm{~K}) ; 0.326(413 \mathrm{~K})$ \\
\hline Dynamic viscosity $\left(\mathrm{kg} \mathrm{m}^{-1} \mathrm{~s}^{-1}\right)$ & $2.7749 \mathrm{X} 10-5 \mathrm{~T} 2-0.0231747 \mathrm{~T}+4.844$ \\
\hline
\end{tabular}

The cases here analyzed are: $\operatorname{Re}=1.0 \times 10^{4}, 2.0 \times 10^{4}$ and $2.6 \times 10^{4}$, considering a temperature difference $(\Delta \mathrm{T})$ between the PCM melting point and the external flow temperature equal to 5,10 and $15 \mathrm{~K}$, for each of the three sphere positions, totaling 27 cases. Two extra conditions were contemplated, using $\Delta \mathrm{T}=15 \mathrm{~K}$ and position $1: \mathrm{Re}=$ $1.0 \times 10^{4}$ and $2.6 \times 10^{4}$ considering a mean heat transfer coefficient $\left(\bar{h}_{\text {ext }}\right)$ equal to 145 and $216 \mathrm{~W} / \mathrm{m}^{2} \mathrm{~K}$, respectively.

\section{MATHEMATICAL AND NUMERICAL MODEL}

The mathematical model used for solving the problem consists of the conservation of mass, momentum and energy equations, according to the treatment illustrated in Ref. [21]. It is assumed as unsteady, laminar and incompressible flow. The mass conservation is given by:

$$
\frac{\partial \rho}{\partial t}+\nabla \cdot(\rho \vec{V})=0
$$

where $\vec{V}$ is the velocity vector, $\rho$ is the density and $t$ is the time. Besides the usual equations for fluid-dynamics and heat transfer problem, the model here adopted utilizes a modality proposed by Brent et al. in Ref. [33] named "enthalpy-porosity method". This method considers the interface between the liquid and solid phases (partially melted 
region) as a porous zone. The model introduces a source term (S) in the momentum equation, as shown below:

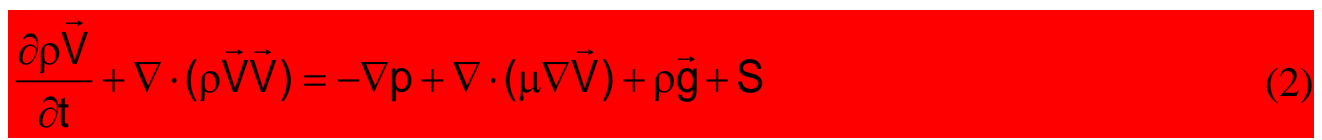

where $\mathrm{p}$ is the pressure, $\mu$ is the dynamic viscosity and $\vec{g} \mathrm{~g}$ is the gravity acceleration. The above-mentioned source term, $\mathrm{S}$, is:

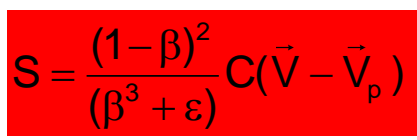

where $\varepsilon$ is a small value ( 0.001$)$ to avoid divisions by zero, $\mathrm{C}$ (mushy zone constant) is a constant proposed in Ref. [33] and $\overrightarrow{V_{p}}$ is the pull velocity. The source term introduces a velocity damping in the transition region between the solid and liquid regions, causing the velocity to be equal to zero at the solid region and maximum at the liquid region. The $\mathrm{C}$ constant indicates the magnitude of said damping: the bigger its value, the bigger the damping. The pull velocity is the velocity at which the solid is pulled out of the domain, which does not happen in this study. It is, therefore, zero in all studied cases in this paper. The liquid fraction $(\beta)$ is obtained from the temperature:

$$
\beta=\left\{\begin{array}{ccc}
0 & \text { if } & T<T_{s} \\
1 & \text { if } & T>T_{1} \\
\frac{T-T_{s}}{T_{1}-T_{s}} & \text { if } & T_{s}<T<T_{1}
\end{array}\right\}
$$

where $T_{s}$ is the solid material temperature and $T_{1}$ is the liquid temperature. The energy conservation equation is given by:

$$
\frac{\partial(\rho \lambda)}{\partial \mathrm{t}}+\nabla(\rho \overrightarrow{\mathrm{V}} \lambda)=\nabla \cdot(\mathrm{k} \nabla \mathrm{T})
$$


where $\lambda$ is the enthalpy, obtained by the sum of the sensible enthalpy $\left(\lambda_{\text {se }}\right)$ and the variation of enthalpy during the phase change $\left(\lambda_{\text {la }}\right)$. The sensible enthalpy is calculated as:

$$
\lambda_{\text {se }}=\lambda_{\text {ref }}+\int_{T_{\text {ref }}}^{T} c_{p} d T
$$

where $\lambda_{\text {ref }}$ is the enthalpy at the reference temperature $\left(\mathrm{T}_{\text {ref }}\right)$. The enthalpy during phase change is obtained as $\lambda_{\mathrm{la}}=\beta \mathrm{L}$, where $\mathrm{L}$ is the latent heat of fusion.

To describe the relation between the PCM and air, the VOF (Volume of Fluid) model is used [21], which determines the volumetric fraction for the PCM through the following equation:

$$
\frac{\partial\left(\alpha_{n}\right)}{\partial t}+\nabla\left(\alpha_{n} \vec{V}\right)=0
$$

where $\alpha_{\mathrm{n}}$ is the primary phase volumetric fraction at the $\mathrm{nth}$ computational cell. The mesh elements at the air-PCM interface have intermediate values of $\alpha$, between 1 and 0 . With the expansion of the PCM, the air volume inside the sphere is decreased and its pressure augments. Thus, the air is here considered as an ideal gas.

\subsection{Initial and Boundary Conditions}

The initial temperature (Ti) considered for the PCM and the air is the same, 388 $\mathrm{K}$, which means that it is $3 \mathrm{~K}$ lower than the PCM melting temperature. On the sphere inner wall, a non-slip condition was used.

$$
\begin{aligned}
& t=0\left\{\begin{array}{l}
\vec{V}_{r, \theta=0} \\
T_{r, \theta}=T_{i}
\end{array}\right. \\
& \left.\left.-k \frac{\partial T}{\partial r}\right)_{r=R}=h_{\text {ext }}\left(T_{R}-T_{a m b}\right) ; \quad \vec{v}\right)_{r=R}=0
\end{aligned}
$$


The external temperature $\left(\mathrm{T}_{\mathrm{amb}}\right)$ was considered uniform and equal to 5, 10 or 15 $\mathrm{K}$ above the PCM melting temperature.

\subsection{Simulation Control}

The convergence criteria here adopted in all cases are: $10^{-8}$ for the energy conservation equation and $10^{-5}$ for the momentum as well as the mass conservation equation. The simulations have been performed using double precision. The underrelaxation factors are: 0.5 for pressure, field forces and momentum, 0.2 for liquid fraction, 0.9 for energy and 0.6 for density. The pressure-velocity coupling has been computed using the PISO method, while PRESTO was used for pressure correction [34]. The Second Order Upwind scheme was utilized for the momentum and energy equations solving. The Geo-Reconstruct method was used to correct the VOF model liquid fraction [35].

As far as time step values (dt), 0.001, 0.01, 0.02 and 0.03 second were tested. Convergence problems occurred using 0.03 s, so this case was discarded. It was verified that the liquid fraction difference during the whole melting process between cases with $\mathrm{dt}$ $=0.02 \mathrm{~s}$ and cases with the other dt values were lower than $0.25 \%$. Thus, $0.02 \mathrm{~s}$ was the

value used in the simulations. The C constant value, defined in Eq. (3), is the same for all cases: $2.0 \times 10^{4}$. The simulation time varied from 8 to 72 hours depending on the case. The commercial code Fluent v18 [35] was used to perform the numerical simulations of this study.

On the outer wall, the values of $h_{\text {ext }}$ presented by Kao et al. in Ref. [29] were prescribed as a function of $\theta$. In order to be converted in boundary conditions, these values were adjusted as equations and then inserted into Fluent as UDF (user-defined functions).

\subsection{Mesh Analysis and Model Validation}

The numerical model being studied is considered bidimensional and symmetric on the vertical axis that crosses the sphere center. Different sized meshes were tested, these have rispettively 8032, 11154 and 14751 volumes. The volume distribution, as well as the refinement near the wall, can be observed in Fig. 4. 
The meshes were tested using the Grid Convergence Index (GCI) proposed by Roache in Ref. [36]. The most unstable case (highest values of $\Delta \mathrm{T}(15 \mathrm{~K}), \operatorname{Re}\left(2.6 \times 10^{4}\right)$ and time step $(\mathrm{dt}=0.02 \mathrm{~s})$ was used to test the meshes. The maximum discretization error between the meshes was $0.6 \%$ in liquid fraction values during the whole melting process. Considering this result, the mesh with 8032 elements has been finally adopted.

The numerical model here developed has been validated by comparing both the numerical and experimental results of Assis et al. [17], using RT27 as PCM [37]. The studied domain [17] consisted of a sphere of diameter D $=80 \mathrm{~mm}$ and with a constant and uniform temperature at the wall as boundary condition. The considered wall temperature is equal to $310 \mathrm{~K}$, which is $10 \mathrm{~K}$ above RT27 mean melting temperature. The sphere is filled with PCM up to $85 \%$ of its height, while the remaining volume is filled with air. The sphere is open at the top, which allows the air to leave and to enter the sphere. The air that returns as backflow is at the same temperature as the wall, $310 \mathrm{~K}$. The initial temperature $\left(\mathrm{T}_{\mathrm{i}}\right)$ for the whole domain is $298 \mathrm{~K}$, which means that there is $2 \mathrm{~K}$ of sub cooling.

Figures 5(a-c) show liquid fraction fields obtained numerically in this work (c), and the results of Assis et al. [23], both experimental (b) and numerical (a), with reference to $t=2,5,20$ and 25 minutes. The blue color represents the solid PCM phase and the red represents the liquid PCM phase while the air is represented by the white color, at the top of the sphere. Comparing the results in different time instants, it is possible to observe that, as time passes, the solid PCM volume decreases and, consequently, the volume of liquid PCM increases. The shape assumed by the PCM as it melts and the liquid layer height are very similar between the results set.

In Figure 6 the liquid fraction variation over time is depicted for the same cases presented in Figure 5. Up to $7.5 \mathrm{~min}$, approximately, the numerical results practically overlap and both are very close to the experimental results. Finally, based on pure observation from Figs. 5 and 6 , it is worth to mention that the the numerical results obtained in this work show very good agreement with the ones found in Ref. [23], especially with those of the experimental campaign. 


\section{RESULTS AND DISCUSSION}

In Figures 7(a-d) the liquid fraction fields are depicted with reference to the following scenarios: $\Delta \mathrm{T}=10 \mathrm{~K}, \mathrm{Re}=2.0 \times 10^{4}$, positions 1,2 and 3 with: $\beta=0.25,0.5$, 0.75 and 0.97 , respectively. It is observable that there are not many differences in the shapes assumed by the PCM between the diverse sphere positions, considering the same liquid fraction values. However, the solid mass decreases over time, always in contact with the base of the sphere. Figures $8(a-c)$ highlight the liquid fraction over time for different Re, $\Delta \mathrm{T}$ and sphere positions. More precisely, in Fig. 8(a), it can be observed that the higher the $\Delta \mathrm{T}$, the shorter the time needed to achieve complete melting $(\beta=1)$, independently the sphere position. Also, for a same $\Delta \mathrm{T}, \beta$ has a weak variation between various sphere positions. Besides, the rate in which $\beta$ increases gets smaller as time passes. For instance, considering the case with $\mathrm{Re}=2.0 \times 10^{4}$ and $\Delta \mathrm{T}=15 \mathrm{~K}$, the time needed for the sphere at position 1 to achieve $\beta=0.5$ is about 4 min. For the same case, the time needed to achieve $\beta=1$ (complete melting) is about $12 \mathrm{~min}$. This means that in $30 \%$ of the total melting time, $50 \%$ of the total available thermal storage capacity is achieved. The above mentioned considerations demonstrates that the process under investigation is more effective at the early stages of melting. Thus, being necessary to store a certain amount of thermal energy in a determined time internal, one alternative may be to increase the PCM quantity in such a modality that only a half can be melted in the same time interval. In Fig. 8(c), it can be noted that the trend of $\beta$ is similar in all the scenarios: the prevalent variation over time occurs at the beginning of the process. Also, it can be noted that the results are grouped with the same Re values. However, as Re increases, the sphere position influence over $\beta$ decreases. More in details, for a certain $\Delta \mathrm{T}$, the total melting time is inversely proportional to Re. For example, with reference to the case with $\Delta \mathrm{T}=5 \mathrm{~K}$, the time needed to achieve $\beta=0.5$, considering $\operatorname{Re}=1.0 \times 10^{4}$ and $2.0 \times 10^{4}$, is approximately 17.5 and $12 \mathrm{~min}$, respectively. Besides, it is interesting to note that the results with $\operatorname{Re}=2.6 \times 10^{4}$ and $\Delta \mathrm{T}=10 \mathrm{~K}$ are almost identical to those with, $\operatorname{Re}=$ $1.0 \times 10^{4}$ and $\Delta \mathrm{T}=15 \mathrm{~K}$. This demonstrates that, with a large increase in Re value, it is possible for a case with lower temperature to have a behaviour similar to a scenario with higher $\Delta \mathrm{T}$. In other words, it is possible to compensate a low $\Delta \mathrm{T}$ with a high Re. 
Table 2 shows the total melting time for all cases with variable $h_{\text {ext }}$, which are: $\mathrm{Re}$ $=1.0 \times 10^{4}, 2.0 \times 10^{4}$ and $2.6 \times 10^{4}, \Delta \mathrm{T}=5,10$ and $15 \mathrm{~K}$ and the three different sphere positions, summing in total 27 cases. Initially, for this table, it can be observed that to higher values of $\Delta \mathrm{T}$ correspond lower time intervals needed to achieve complete melting, considering the same Re number and sphere position. The melting time also shows a weak variation between the different sphere positions: any way, even if not remarkable, this difference is inversely proportional to $\Delta \mathrm{T}$ and Re.

Table 2 - Total melting time for all cases with variable $h_{\mathrm{ext}}$

\begin{tabular}{ccccccccccc}
\hline \hline \multicolumn{1}{c}{ Position $(\mathrm{K})$} & 5 & 10 & 15 & 5 & 10 & 15 & 5 & 10 & 15 \\
\hline \hline \multicolumn{7}{c}{$\mathrm{Re}=1.0 \times 10^{4}$} & \multicolumn{3}{c}{$\mathrm{Re}=2.0 \times 10^{4}$} & $\mathrm{Re}=2.6 \times 10^{4}$ \\
\hline 1 & 39.9 & 22.7 & 15.5 & 31.0 & 17.1 & 11.9 & 27.5 & 15.2 & 10.7 \\
2 & 43.2 & 23.8 & 15.9 & 32.2 & 17.7 & 12.0 & 28.3 & 15.6 & 10.9 \\
3 & 46.5 & 25.7 & 16.7 & 32.8 & 18.1 & 12.6 & 28.6 & 15.7 & 11.0 \\
\hline \hline
\end{tabular}

Still in relation to Table 2, it is also worthy of note that, doubling the value of $\Delta \mathrm{T}$, from 5 to $10 \mathrm{~K}$, the total melting time decreases about $46 \%$, considering the case in position 1 and $\mathrm{Re}=2.0 \times 10^{4}$. Further increasing $\Delta \mathrm{T}$ by $50 \%$, from 10 to $15 \mathrm{~K}$, the total melting time decreases $36 \%$. This behaviour is similar with reference to all the remaining cases. Finally, the effect of Re over the total melting time is also worth of interest. For instance, with reference to the case with $\Delta \mathrm{T}=15 \mathrm{~K}$ and position 1 , doubling the Re value from $1.0 \times 10^{4}$ to $2.0 \times 10^{4}$, the melting time decreases about $30 \%$. On the contrary, augmenting the Re value of $30 \%$, from $2.0 \times 10^{4}$ to $2.6 \times 10^{4}$, it decreases the melting time by only $10 \%$.

Table 2 also shows another interesting result: irrespective of $\Delta \mathrm{T}$ and $\mathrm{Re}$, the sphere located at position 1 is that which first reaches the complete melt. Conversely, the sphere in position 3 is the last to reach this condition. At this moment it is important to remember that, in this numerical work, we used as boundary condition experimental results of the heat transfer coefficient (hext) presented by Kao et al. [29] and showed in Figure 2 (b). In this figure it can be observed that the major external $\mathrm{h}$ is the sphere in position 1 and that the smallest external $\mathrm{h}$ is referring to position 3 . With these observations one can realize two important observations: (a) the heat transfer rates for the spheres are 
effectively altered as a function of their position in the matrix, and (b) the boundary conditions used in the different spheres, effectively, also represent their arrangement in the matrix.

Since the location of the beads in the matrix interferes with the heat transfer rates and consequent melt rates, it is interesting to analyze the absorbed total heat $\left(Q_{s t, l a}=\operatorname{Lm} \beta\right)$. Figure 9 shows the stored latent thermal energy $\left(\mathrm{Q}_{\text {st, la }}\right)$ vs. time for each sphere, considering $\Delta \mathrm{T}=5 \mathrm{Ke} \operatorname{Re}=1.0 \times 10^{4}$. Initially, it can be observed that $\mathrm{Q}_{\mathrm{st}}$, la is dependent on the position of the spheres. In addition, it is noted that the difference between the amount of heat stored in each sphere increases over time until the sphere in position 1 reaches the complete meltdown, when it reaches approximately $507 \mathrm{~J}$ of energy stored in 33 minutes. At this same time, the amount of energy stored in the 2 and 3 position spheres is approximately $487 \mathrm{~J}$ and $469 \mathrm{~J}$ respectively. In this case, for this time and considering the energy conditions of the positional spheres in the matrix, the total heat quantity of the matrix is $1463 \mathrm{~J}$. This means that if the positioning of the spheres had not been considered, they would all have stored the the same amount of heat as the sphere of position 1, $507 \mathrm{~J}$. In this case the total heat stored by the matrix would be $521 \mathrm{~J}$, i.e. oversized in relation to the actual conditions.

\subsection{Heat Flux on the Wall}

Figures 10(a-d) highlight the local heat flux values (q"'local) and temperature along the wall $\left(\mathrm{T}_{\text {wall }}\right)$ with reference to position $1, \Delta \mathrm{T}=15 \mathrm{~K}$ and $\mathrm{Re}=2.0 \times 10^{4}$. In Figures $11(\mathrm{a}-$ d) the liquid fraction fields are depicted uder the same conditions; only half of the sphere is shown, due to symmetry. It is worth to mention that, for a better understanding between the $\beta$ fields (Fig. 11(a-d)) and the q" values over $\theta$ (Fig. 10(a-d)), the $\beta$ fields have been rotated 90 degrees counter clock wise. Both results sets are related to different $\beta$ during the melting process, precisely $\beta=0.25,0.5,0.75$ and 0.97 . Based on visual observation, for $\beta=0.25$, the q'" local profile is similar to the $h_{\text {ext }}$ profile used as boundary condition (see Figure 2(b)), but only when the angle $\theta$ exceeds $30^{\circ}$. As $\beta$ augments, the q'" local profile changes with a decreasing trend. This change is associated with the increase in

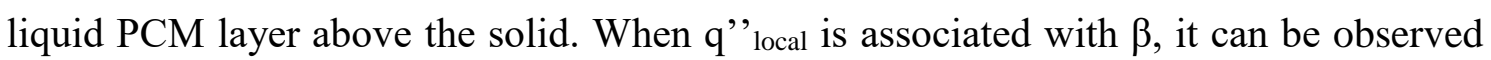
that, at the liquid PCM region, there is also an increase in q"' local values as it gets closer to the solid region. This happens due to a thermal stratification at the liquid PCM, causing 
the highest temperature to occur at the top of the sphere, while the lowest temperature is at the sphere bottom, next to the solid PCM. However, the air temperature is almost uniform during the whole process, since the air specific heat is significantly lower than the PCM's. Still in relation to Figures 11(a-d), at the solid PCM region, the heat flux profile is similar to that of $h_{\text {ext }}$, since the wall temperature at this region is almost constant and uniform. Also, the heat flux at the base $\left(\theta=180^{\circ}\right)$ is practically constant during the whole phase change process. This is due to buoyancy, caused by the temperature and consequent density changes, causing solid PCM to be always present at the sphere bottom while the melting process lasts.

\subsection{Comparison Between Uniform $h$ and $h$ as a Function of $\theta$}

Figure 12 highlights the temporal trend of the volume fraction $\beta$ using both a uniform value of $h_{\text {ext }}$ and $h_{\text {ext }}$ function of $\theta$ (condition being studied thus far), considering $\operatorname{Re}=10^{4}$, and $2.6 \times 10^{4}$, position 1 and $\Delta \mathrm{T}=15 \mathrm{~K}$. In this diagram, it can be noted that independently of the Re number, the use of uniform and non-uniform $h_{\text {ext }}$ induces different values of $\beta$. Besides, this influence becomes less pronounced for high values of the Reynolds number, whilst considering $\mathrm{Re}=2.6 \times 10^{4}$, both solutions have very similar values up to $\beta=0.5$. On the contrary, considering $\operatorname{Re}=1.0 \times 10^{4}$, both the above mentioned $h_{\text {ext }}$ conditions show very different results during all the melting process. These observations related to the use of a uniform value of $h_{\text {ext }}$, show that the melting time (obtained numerically) depends on the type of boundary condition being used and this dependency varies for different Re values.

Figures 13(a-d) show liquid fraction fields for $\mathrm{Re}=2.6 \times 10^{4}$, position 1 and $\Delta \mathrm{T}=$ $15 \mathrm{~K}$, at $\mathrm{t}=2,5,7.5$ and $10 \mathrm{~min}$, using the same $\mathrm{h}_{\mathrm{ext}}$ conditions as shown previously (uniform and $\mathrm{f}(\theta)$ ). At $\mathrm{t}=2$ and $5 \mathrm{~min}$, the solid PCM mass is almost the same for both cases. However, they differ in shape slightly. At $t=2 \mathrm{~min}$, the case with uniform $\mathrm{h}_{\text {ext }}$ shows a small elevation in the central region, which does not happen with $h_{\mathrm{ext}}=f(\theta)$. At the final time intervals, the solid PCM mass is considerably smaller for the non-uniform condition.

Figures 14(a-d) highlight liquid fraction fields for $\operatorname{Re}=10^{4}$, position 1 and $\Delta \mathrm{T}=$ $15 \mathrm{~K}$, at $\mathrm{t}=2,5,7.5$ and $10 \mathrm{~min}$, for both $\mathrm{h}_{\text {ext }}$ conditions. It can be noted that, during the 
whole melting process, the amount of solid PCM and its shape are considerably different between the two $h_{\mathrm{ext}}$ conditions. At $\mathrm{t}=3 \mathrm{~min}$, the solid PCM shape is significantly different from one case to the other. Considering the non-uniform condition, the solid PCM layer is practically flat in the interface between the solid and liquid layers. On the other hand, the uniform condition does not present this flat shape and there is a solid mass accumulation at the region close to the symmetry axis. The above mentioned differences, in relation to the melting time, $\beta$ behavior and solid PCM shape, shown in Figures 13 and 13 , evidence that it may be more appropriate to use the non-uniform $h_{\text {ext }}$ condition along the entire wall, instead of using the simplified condition of uniform $h_{\text {ext }}$, especially for low values of Re. Considering cases with $\mathrm{Re}=2.6 \times 10^{4}$, the uniform condition of $\mathrm{h}_{\mathrm{ext}}$ has a smaller melting time.

\section{CONCLUDING REMARKS}

The present work illustrates the outcomes of the melting process in PCMcontaining pebble bed thermal storage systems. The numerical model incorporates the following phenomena: external convection process, heat conduction through metal walls, natural convection of the liquid phase, volumetric expansion and the downward movement of the solid phase. Therefore, in the present paper effects only partially considered in previous literature have been mutually contemplated. Variable heat flow was also introduced through the use of local heat transfer coefficient profiles to represent the external flow. The validation of the model was performed by means of comparison with the experimental and numerical results available in literature, using RT27 as PCM. After validation, the same model was employed to analyze the erythritol melting process. Local heat transfer coefficient profiles for Re values of $1.0 \times 10^{4}, 2.0 \times 10^{4}$ and $2.6 \times 10^{4}$ were studied in combination with three different positions within the storage unit. Three different temperatures for the external flow were also included, precisely 5,10 and $15 \mathrm{~K}$ above the PCM melting temperature.

Many ideas emerged from this work. The results have led us to report the following main conclusions: 
- the temperature difference, the Reynolds number and the sphere position directly affect the total melting time, being in this order the degree of importance;

- the influence of the position decreases with the augmentation of Re;

- the effect of smaller $\Delta \mathrm{T}$ can be compensated by increasing Re. However, this increase needs to be significantly elevated;

- it is more appropriate to use the variable $h_{\text {ext }}$ condition along the entire wall, rather than using the simplified uniform $\mathrm{h}_{\text {ext }}$ condition, especially for low Re values.

\section{Acknowledgements.}

The authors J. F. Raymundo Junior, R. De Cesaro Oliveski, and L.A. O. Rocha thanks to FAPERGS, Porto Alegre, RS, Brazil, and CNPq, Brasília, DF, Brazil, by the financial support. The author Cesare Biserni was sponsored by the Italian Ministry for Education, University and Research.

\section{References}

[1] M. Ghalambaz, A. Doostani, A. J. Chamkha, M. A. Ismael, "Melting of nanoparticlesenhanced phase-change materials in an enclosure: Effect of hybrid nanoparticles", International Journal of Mechanical Sciences, Vol. 134, pp.85-97, 2017.

[2] N. S. Bondareva, M. A. Sheremet, "Flow and heat transfer evolution of PCM due to natural convection melting in a square cavity with a local heater", International Journal of Mechanical Sciences, Vol. 134, pp.610-619, 2017.

[3] D. L. Zhao, Y. Li, Y. J. Dai, R. Z. Wang, "Optimal Study of a Solar Air Heating System with Pebble Bed Energy Storage”, Energy Conversion and Management, Vol. 52, pp. 2392-2400, 2011.

[4] A. Sharma, V. V. Tyagi, C. R. Chen, D. Buddhi, "Review on Thermal Energy Storage with Phase Change Materials and Applications", Renewable and Sustainable Energy Reviews, Vol. 13, pp. 318-45, 2009.

[5] I. Dincer, M. Rosen, "Thermal Energy Storage Systems and Applications. Fuel Cells, Batt Energy Storage”, 1st ed., Wiley, 2011.

[6] A. Gil, M. Medrano, I. Martorell, A. Lázaro, P. Dolado, B. Zalba, L. F. Cabeza, "State of the Art on High Temperature Thermal Energy Storage for Power Generation. Part 1Concepts, Materials and Modellization", Renewable and Sustainable Energy Reviews, Vol. 14, pp. 31-55, 2010.

[7] S. Karthikeyan, G. Ra. Solomon, V. Kumaresan, R. Velraj, "Parametric Studies on Packed Bed Storage Unit Filled with PCM Encapsulated Spherical Containers for Low 
Temperature Solar Air Heating Applications", Energy Conversion and Management, Vol. 78, pp. 74-80, 2014.

[8] S. Kuravi, J. Trahan, D. Y. Goswami, M. M. Rahman, E.K. Stefanakos, "Thermal Energy Storage Technologies and Systems for Concentrating Solar Power Plants", Progress in Energy and Combustion Science, Vol. 39, pp. 285-319, 2013.

[9] N.A.M. Amin, F. Bruno, M. Belusko, "Effective Thermal Conductivity for Melting in PCM Encapsulated in a Sphere", Applied Energy, Vol. 122. pp. 280-87, 2014.

[10] R. Baby, C. Balaji, "Thermal Performance of a PCM Heat Sink under Different Heat Loads: An Experimental Study", International Journal of Thermal Sciences, Vol. 79, pp. 240-249, 2014.

[11] P. Gimenez-Gavarrell, S. Fereres, "Glass Encapsulated Phase Change Materials for High Temperature Thermal Energy Storage”, Renewable Energy, Vol. 107, pp. 497-507, 2017.

[12] W. Li, Y.H. Wang, C.C. Kong, "Experimental Study on Melting/solidification and Thermal Conductivity Enhancement of Phase Change Material inside a Sphere", International Communications in Heat and Mass Transfer, Vol. 68, pp. 276-82, 2015.

[13] M. Termirel, H. Hu, H. Shabgard, P. Boettcher, M. McCarthy, Y. Sun, "Solidification of Additive-Enhanced Phase Change Materials in Spherical Enclosures with Convective Cooling”, Applied Thermal Engineering, Vol. 111, pp. 134-42, 2017.

[14] W. Li, S. G. Li, S. Guan, Y. Wang, X. Zhang, X. Liu, "Numerical Study on Melt Fraction during Melting of Phase Change Material inside a Sphere", International Journal of Hydrogen Energy, Vol. 42, pp. 18232-18239, 2017.

[15] A. R. Archibold, M.M. Rahman, D. Y. Goswami, E. K. Stefanakos, "Analysis of Heat Transfer and Fluid Flow during Melting inside a Spherical Container for Thermal Energy Storage", Applied Thermal Engineering, Vol. 64, pp. 396-407, 2014.

[16] E. Assis, G. Ziskind, R. Letan, "Numerical and Experimental Study of Solidification in a Spherical Shell”, Journal of Heat Transfer, Vol. 131, pp. 24502, 2009.

[17] E. Assis, L. Katsman, G. Ziskind, R. Letan, "Numerical and Experimental Study of Melting in a Spherical Shell”, International Journal of Heat and Mass Transfer, Vol. 50, pp. 1790-1804, 2007.

[18] V. Shatikian, G. Ziskind, R. Letan, "Numerical Investigation of a PCM-Based Heat Sink with Internal Fins", International Journal of Heat and Mass Transfer, Vol. 48, pp. 3689-3706, 2005.

[19] V. Shatikian, G. Ziskind, R Letan, "Numerical Investigation of a PCM-Based Heat Sink with Internal Fins: Constant Heat Flux", International Journal of Heat and Mass Transfer, Vol. 51, pp. 1488-1493, 2008. 
[20] F. L. Tan, S. F. Hosseinizadeh, J. M. Khodadadi, L. Fan, "Experimental and Computational Study of Constrained Melting of Phase Change Materials (PCM) inside a Spherical Capsule", International Journal of Heat and Mass Transfer, Vol. 52, pp. 34643472, 2009.

[21] J.H. Nazzi Ehms, R. De Césaro Oliveski, L. A. Oliveira Rocha, C. Biserni, "Theoretical and Numerical Analysis on Phase Change Materials (PCM): A Case Study of the Solidification Process of Erythritol in Spheres", International Journal of Heat and Mass Transfer, Vol. 119, pp. 523-532, 2018.

[22] F.L. Tan, S. C. Fok, "Melt Fraction Estimation Using Solid Modeling for Melting inside a Sphere", Computer Applications in Engineering Education, Vol. 18, pp. 290297, 2010.

[23] Y. T. Lee, S. W. Hong, J. D. Chung, "Effects of Capsule Conduction and Capsule Outside Convection on the Thermal Storage Performance of Encapsulated Thermal Storage Tanks", Solar Energy, Vol. 110, pp. 56-63, 2014.

[24] S.A. Fomin, T S Saitoh, "Melting of Unfixed Material in Spherical Capsule with Non-Isothermal Wall", International Journal of Heat and Mass Transfer, Vol. 42, pp. 4197-4205, 1999.

[25] Y. Varol, A. Koca, H.F. Oztop, E. Avci, "Forecasting of thermal energy storage performance of Phase Change Material in a solar collector using soft computing techniques", Expert Systems with Applications, Vol. 37 (4), pp. 2724-2732, 2010.

[26] H.F. Oztop, Z. Zhao, B. Yu, "Conduction-combined forced and natural convection in lid-driven enclosures divided by a vertical solid partition, International Communications in Heat and Mass Transfer, Vol. 36, pp. 661-668, 2009.

[27] C. Sun, B. Yu, H.F. Oztop, Y. Wang, J. Wei, "Control of mixed convection in liddriven enclosures using conductive triangular fins", International Journal of Heat and Mass Transfer, Vol. 54, pp. 894-909, 2011.

[28] T. Nomura, N. Okinaka, T. Akiyama, "Technology of Latent Heat Storage for High Temperature Application: A Review”, ISIJ International, Vol. 50, pp. 1229-1239, 2010.

[29] M.T. Kao, Y. H. Tung, Y. M. Ferng, C. C. Chieng, M. K. Chyu, “3D Measurements and Numerical Computations of Heat Transfer Coefficients on Spheres in an Array", International Journal of Thermal Sciences, Vol. 68, pp. 110-118, 2013.

[30] F. Agyenim, N. Hewitt, P. Eames, M. Smyth, "A Review of Materials, Heat Transfer and Phase Change Problem Formulation for Latent Heat Thermal Energy Storage Systems (LHTESS)", Renewable and Sustainable Energy Reviews, Vol. 14, pp. 615-628, 2010. 
[31] A. Hesaraki, "CFD Modeling of Heat Charging Process in a Direct-Contact Container for Mobilized Thermal Energy Storage" Mälardalen University Sweden, 2011. http://www.diva-portal.org/smash/get/diva2:430712/fulltext02.

[32] M. Sillick, C.M. Gregson, "Spray Chill Encapsulation of Flavors within Anhydrous Erythritol Crystals”, LWT - Food Science and Technology, Vol. 48, pp. 107-113, 2012.

[33] A.D. Brent, V. R. Voller, K. J. Reid, "Enthalpy-Porosity Technique for Modeling Convection-Diffusion Phase Change: Application to the Melting of a Pure Metal" Numerical Heat Transfer, Vol. 13, pp. 297-318, 1988.

[34] S.V. Patankar, Numerical Heat Transfer and Fluid Flow, Hemisphere, Washington, 1980.

[35] ANSYS Fluent Theory Guide, SAS IP, Inc, 2015.

[36] P. J. Roache, "Perspective: A Method for Uniform Reporting of Grid Refinement Studies", Journal of Fluids Engineering, Vol. 116, pp. 405-413, 1994.

[37] Rubitherm - https://www.rubitherm.eu/en/index.php/productcategory/organischepcm-rt - Accessed on March 12, 2018 


\section{FIGURES}

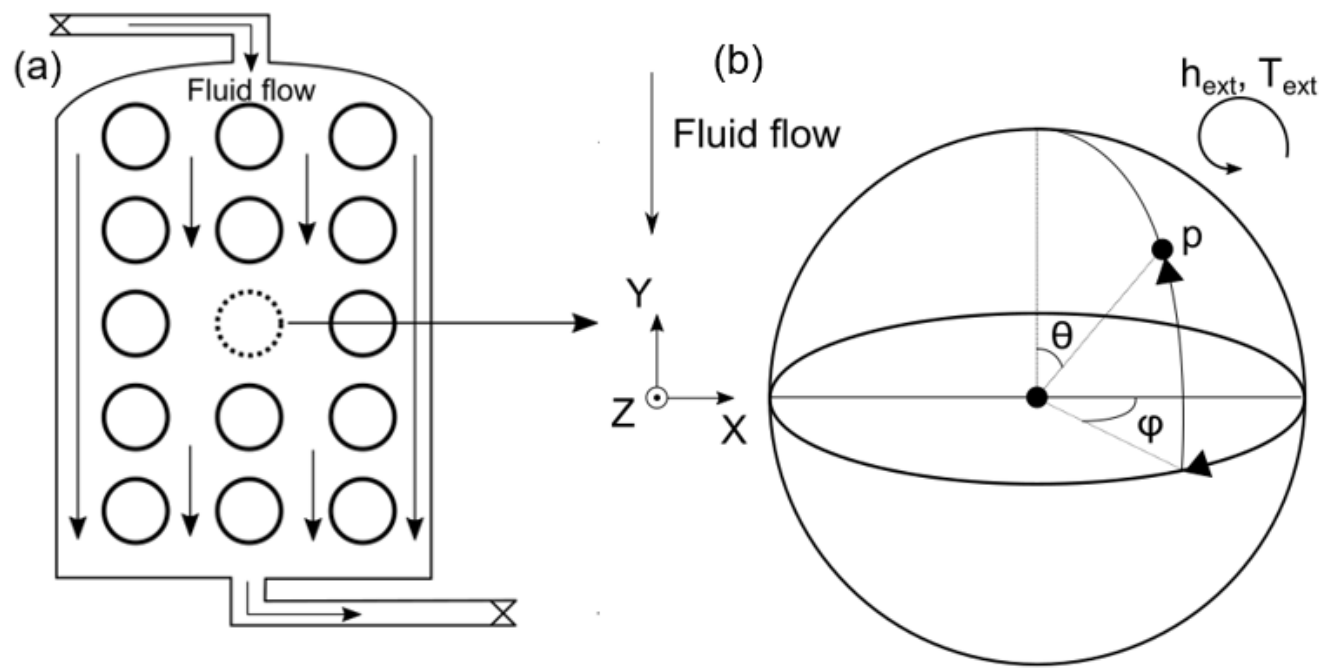

Figure 1 - Pebble bed heat storage unit: (a) representation and (b) sphere angles and axis. 


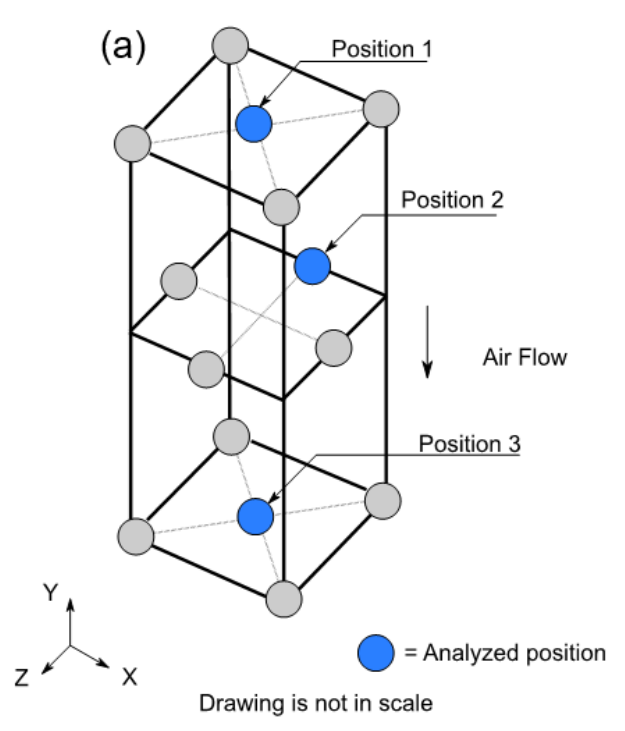

(b)

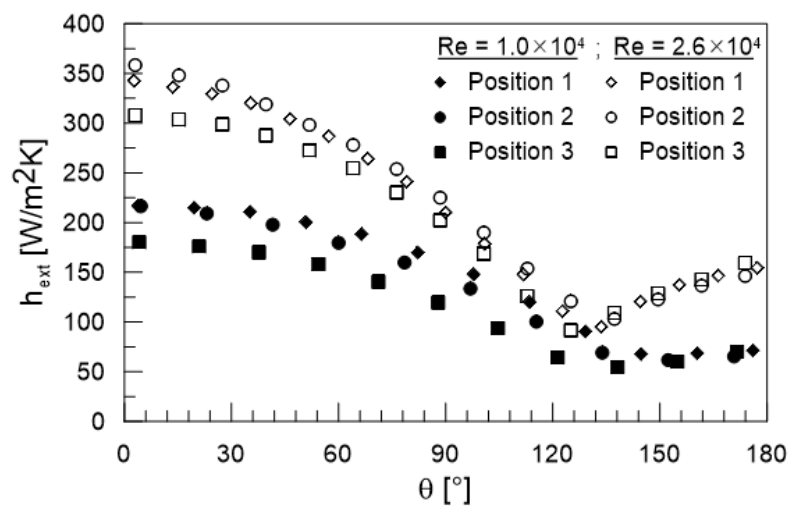

Figure 2 - Sphere identification: (a) array used by Kao et al. [29] and (b) hext as a function of $\theta$, for $\operatorname{Re}=1.0 \times 10^{4}$ and $2.6 \times 10^{4}$, for all three spheres conditions.

Source: adapted from Kao et al. [29].

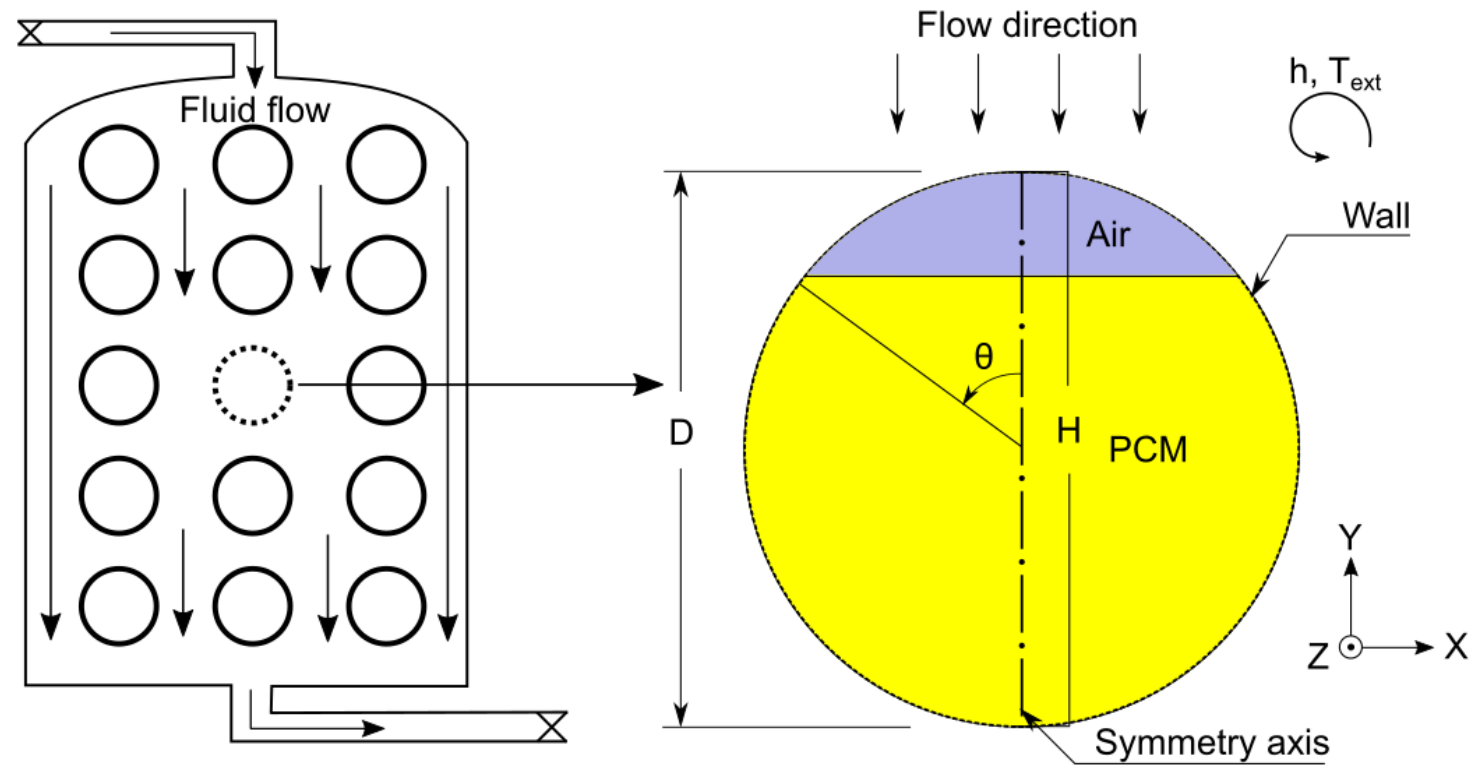

Figure 3 - Physical model representation. 


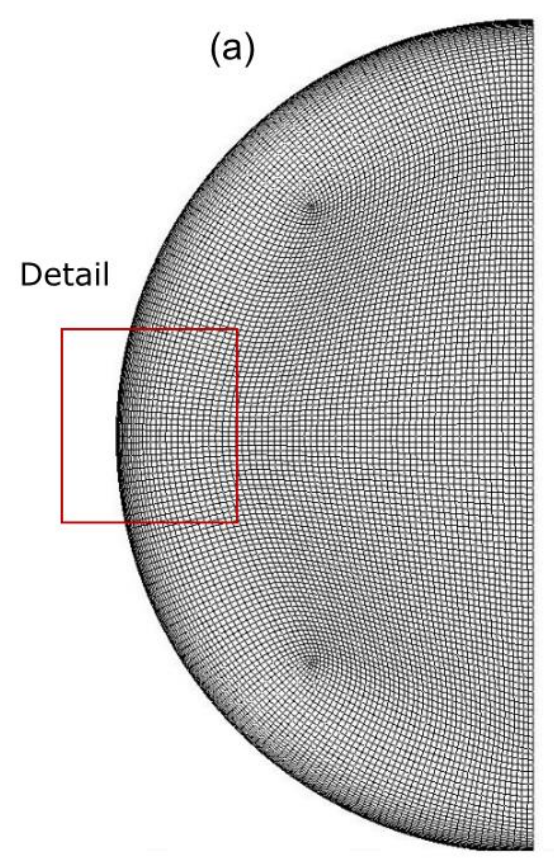

(b) Detail

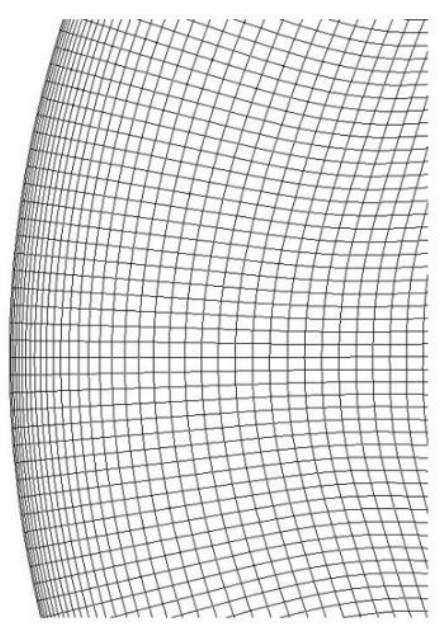

Figure 4 - Computational mesh: (a) complete and (b) wall refinement detail. 
(a)
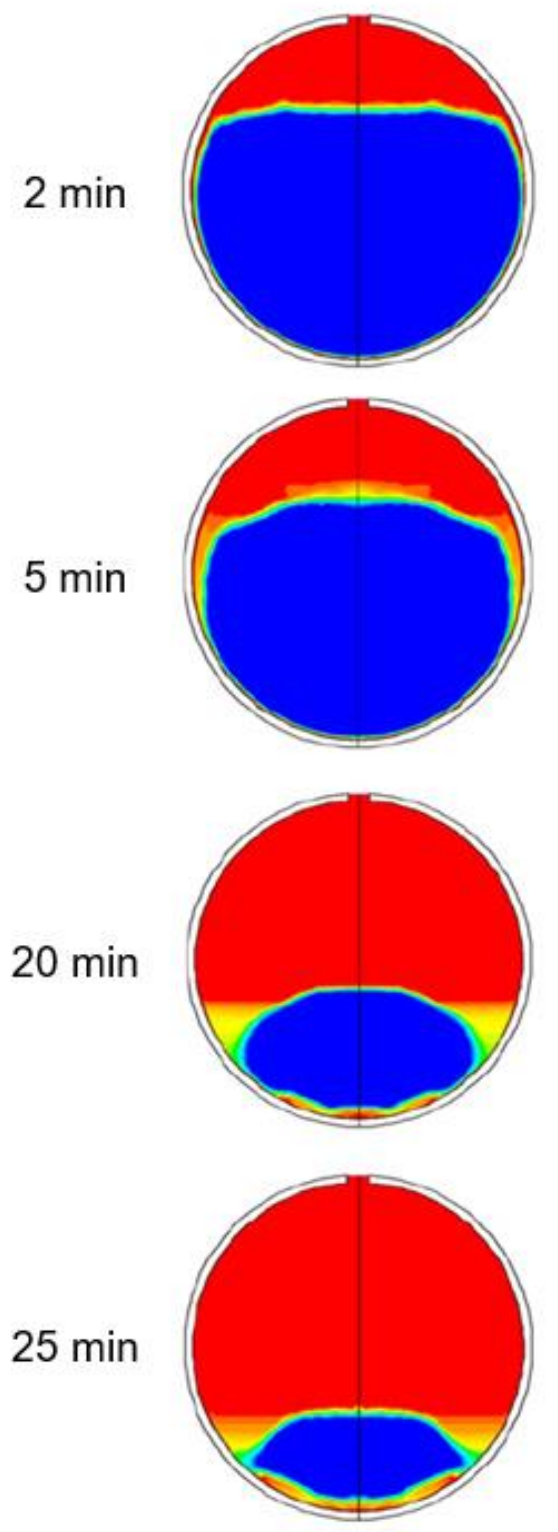

(c)
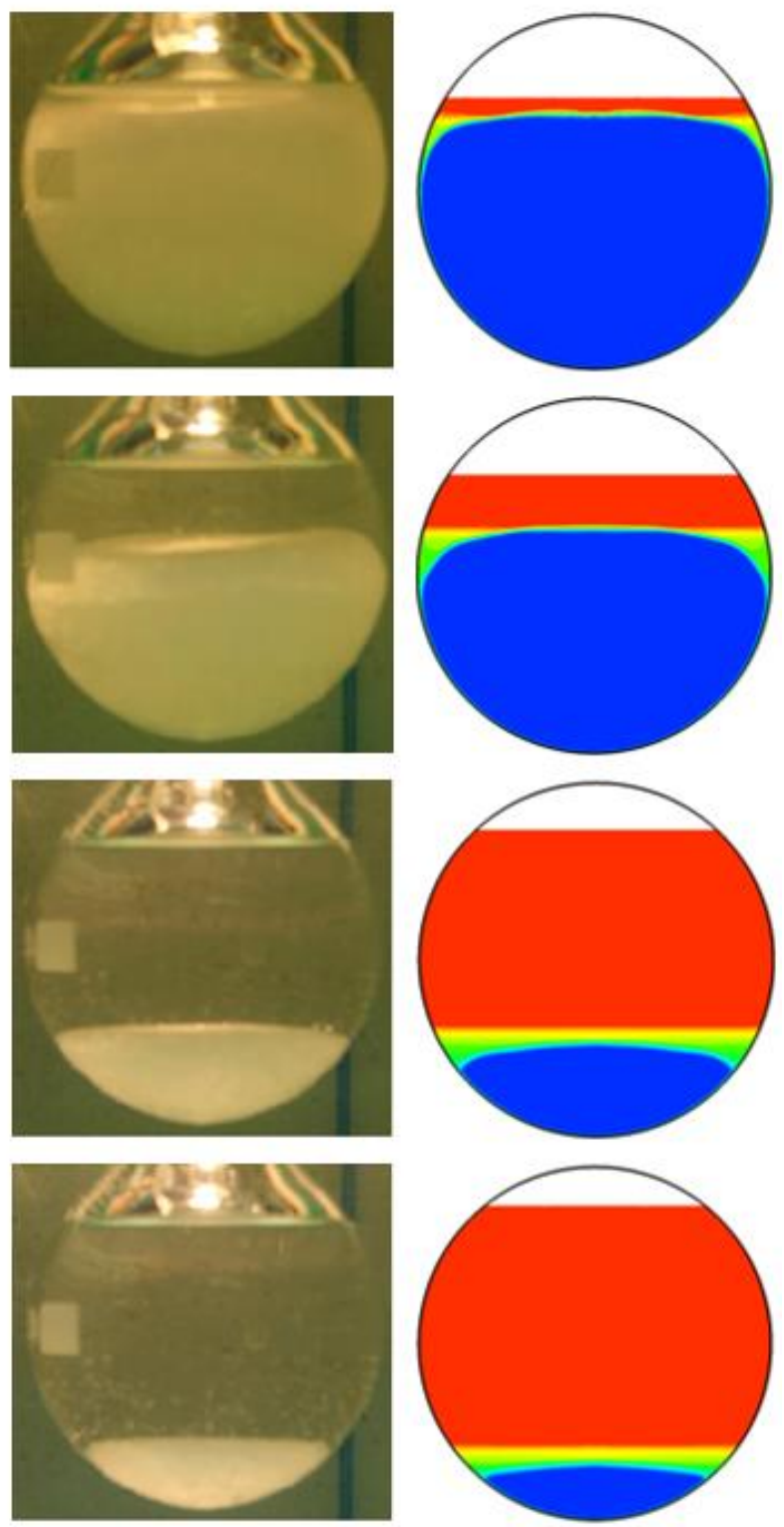

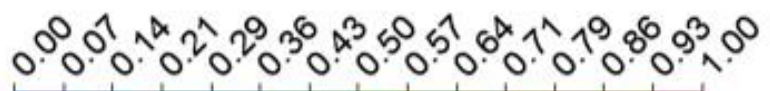

$\beta$

Figure 5 - Liquid fraction field for RT27 for $\mathrm{t}=2,5,20$ and 25 min: (a) numericalAssis et al. [23] (b) experimental-Assis et al. [23] and (c) numerical-present work. 


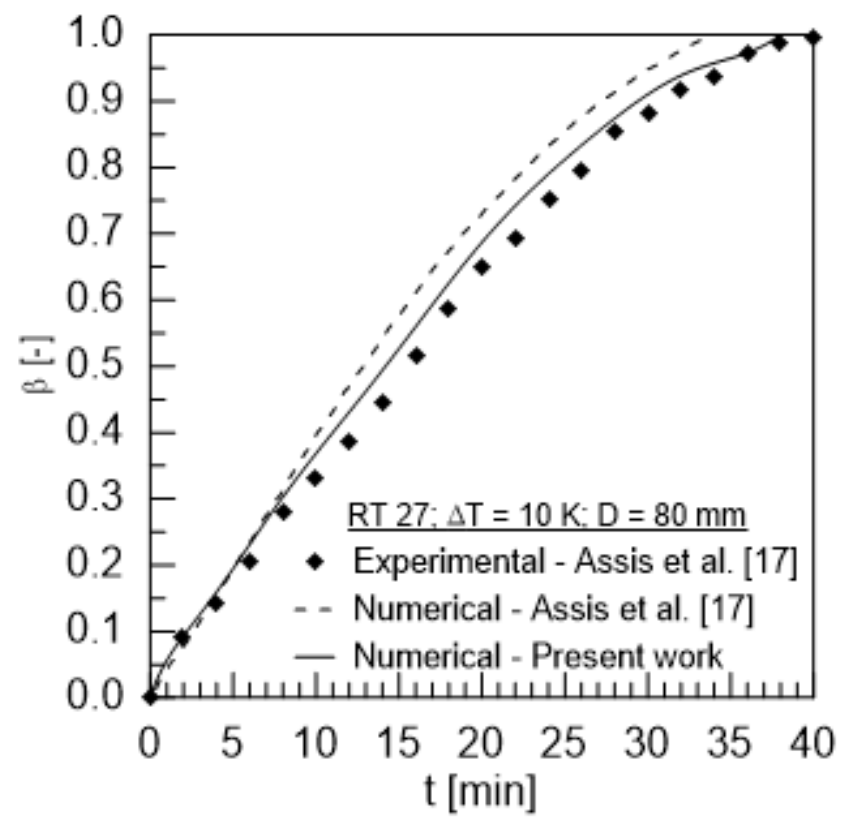

Figure 6 - Liquid fraction over time for RT27, $\Delta \mathrm{T}=10 \mathrm{~K}$ and $\mathrm{D}=80 \mathrm{~mm}$ : comparison with the results obtained by Assis et al. [17]. 


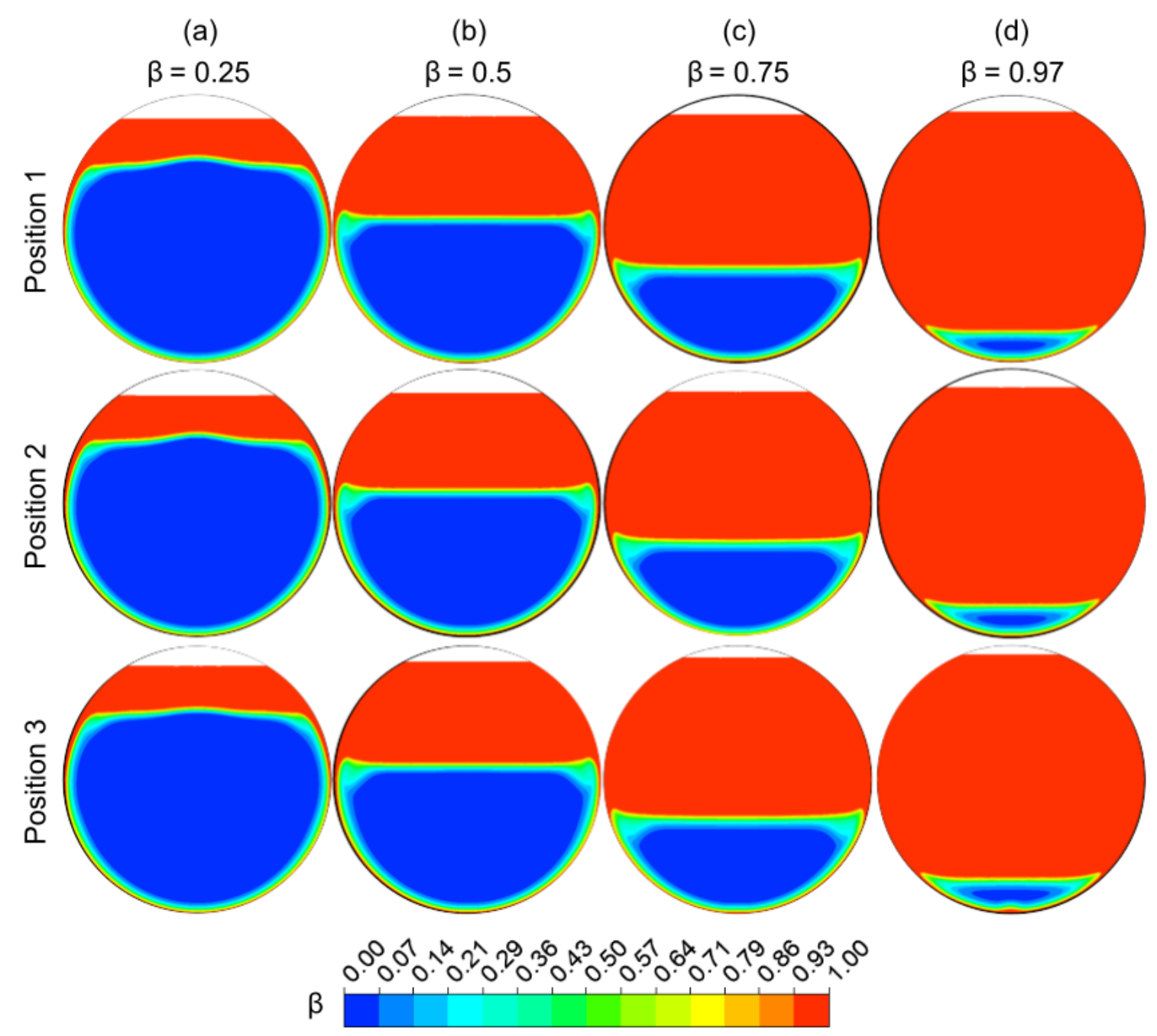

Figure 7 - Liquid fraction field for $\Delta \mathrm{T}=10 \mathrm{~K}, \mathrm{Re}=2.0 \times 10^{4}$ and positions 1,2 and 3 , with: (a) $\beta=0.25$, (b) $\beta=0.5$, (c) $\beta=0.75$ and (d) $\beta=0.97$. 

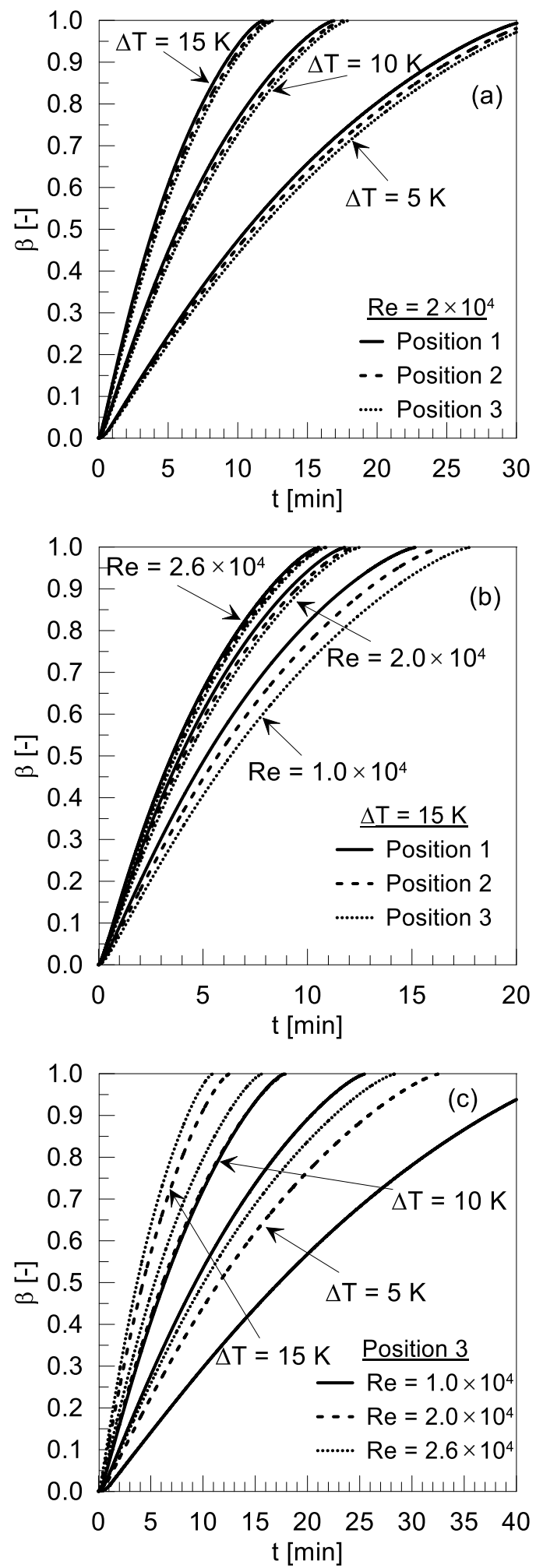

Figure 8 - Liquid Fraction vs. time:

(a) $\mathrm{Re}=2.0 \times 10^{4}, \Delta \mathrm{T}=5,10,15 \mathrm{~K}$ and positions $1,2,3$;

(b) $\Delta \mathrm{T}=15 \mathrm{~K}$, positions $1,2,3$ and $\mathrm{Re}=1.0 \times 10^{4}, 2.0 \times 10^{4}, 2.6 \times 10^{4}$;

(c) position 3 with $\Delta \mathrm{T}=5,10,15 \mathrm{~K}$ and $\mathrm{Re}=1.0 \times 10^{4}, 2.0 \times 10^{4}, 2.6 \times 10^{4}$. 


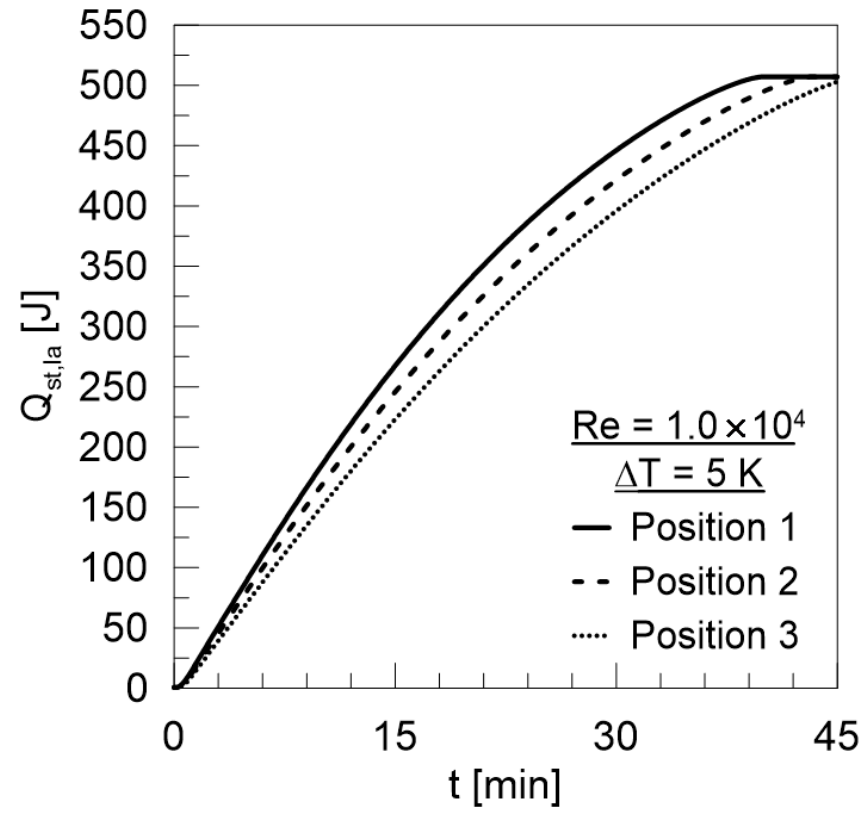

Figure 9 - Latent thermal energy stored vs. time: $\operatorname{Re}=1.0 \times 10^{4}, \Delta \mathrm{T}=5$ and positions 1 , 2, 3; 

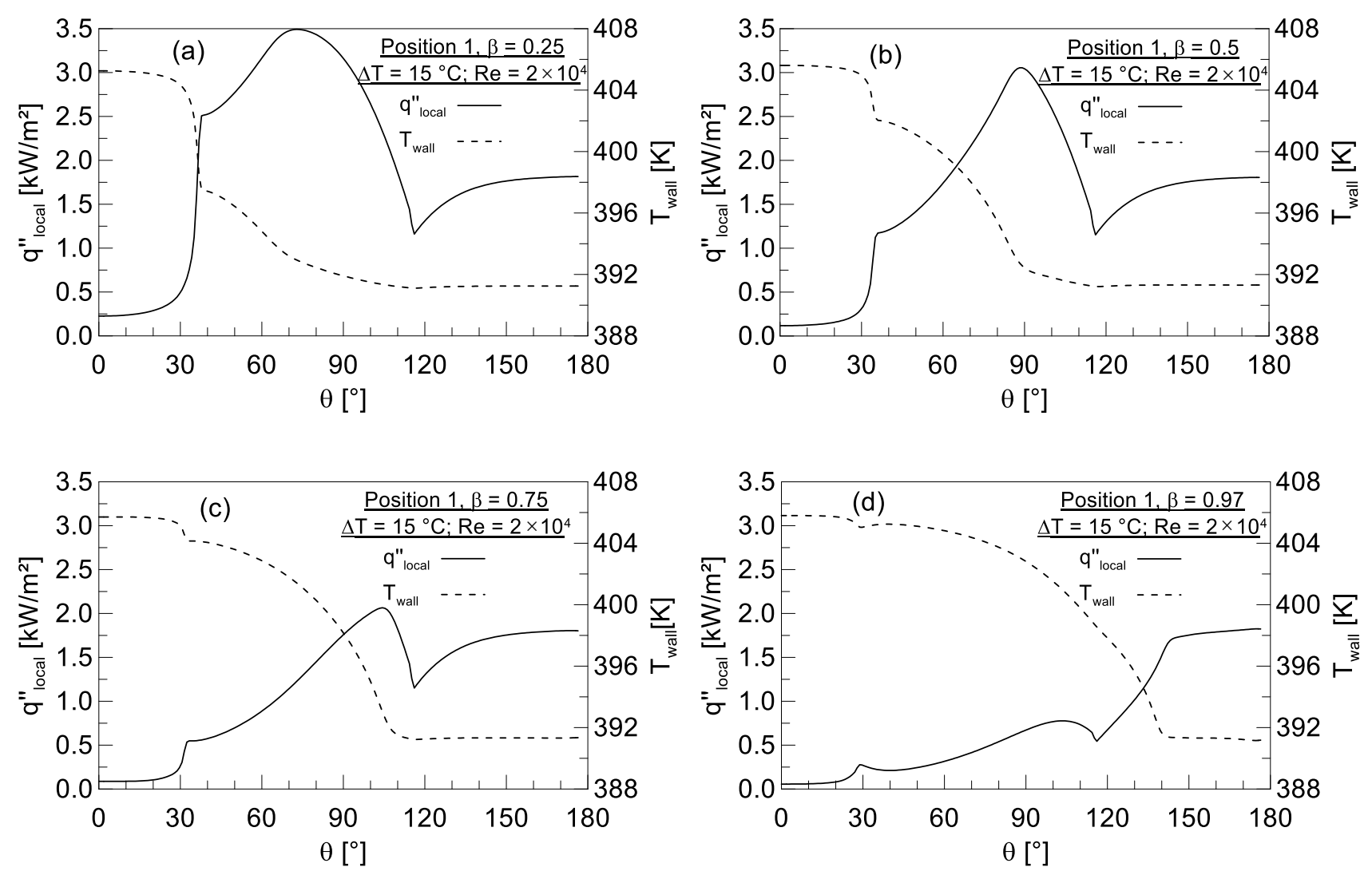

Figure 10 - Local heat flux and wall temperature over $\theta$, for $\beta=0.25(\mathrm{a}), 0.5(\mathrm{~b}), 0.75(\mathrm{c})$, $0.97(\mathrm{~d})$, Position $1, \Delta \mathrm{T}=15 \mathrm{~K}$ and $\mathrm{Re}=2.0 \times 10^{4}$. 

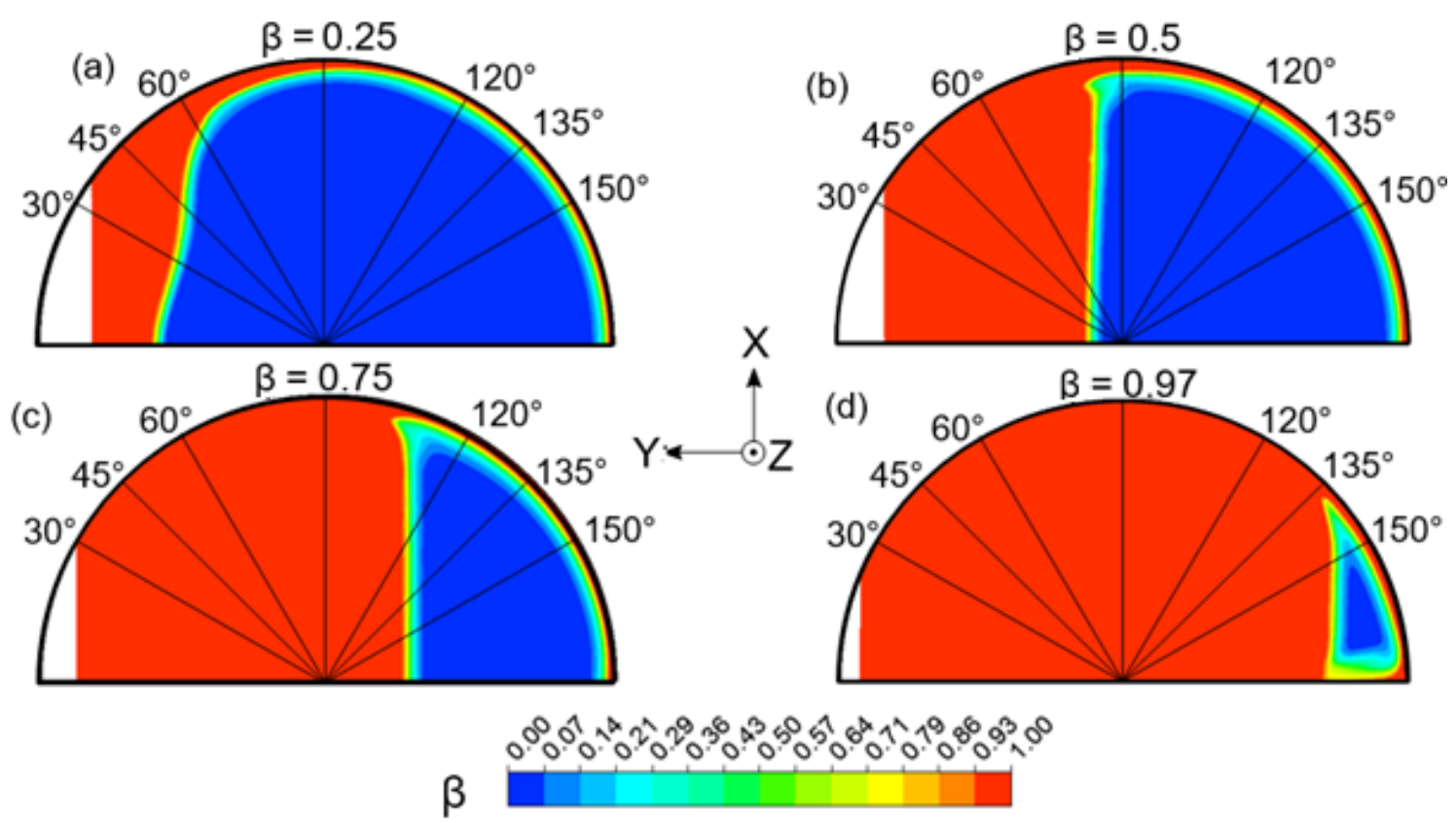

Figure 11 - Liquid fraction fields for $\beta=0.25(\mathrm{a}), 0.5(\mathrm{~b}), 0.75(\mathrm{c}), 0.97(\mathrm{~d})$, Position 1 , $\Delta \mathrm{T}=15 \mathrm{~K}$ and $\mathrm{Re}=2.0 \times 10^{4}$.

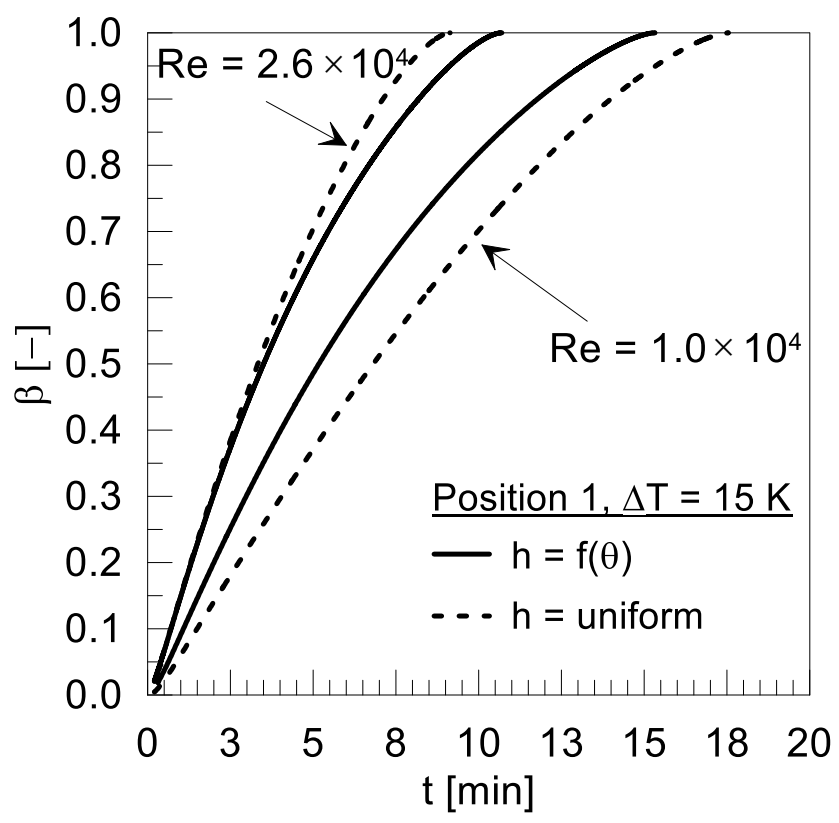

Figure 12 - Liquid fraction over time, Position $1, \Delta \mathrm{T}=15 \mathrm{~K}, \mathrm{Re}=2.6 \times 10^{4}, \mathrm{~h}=$ uniform and $h=f(\theta)$. 


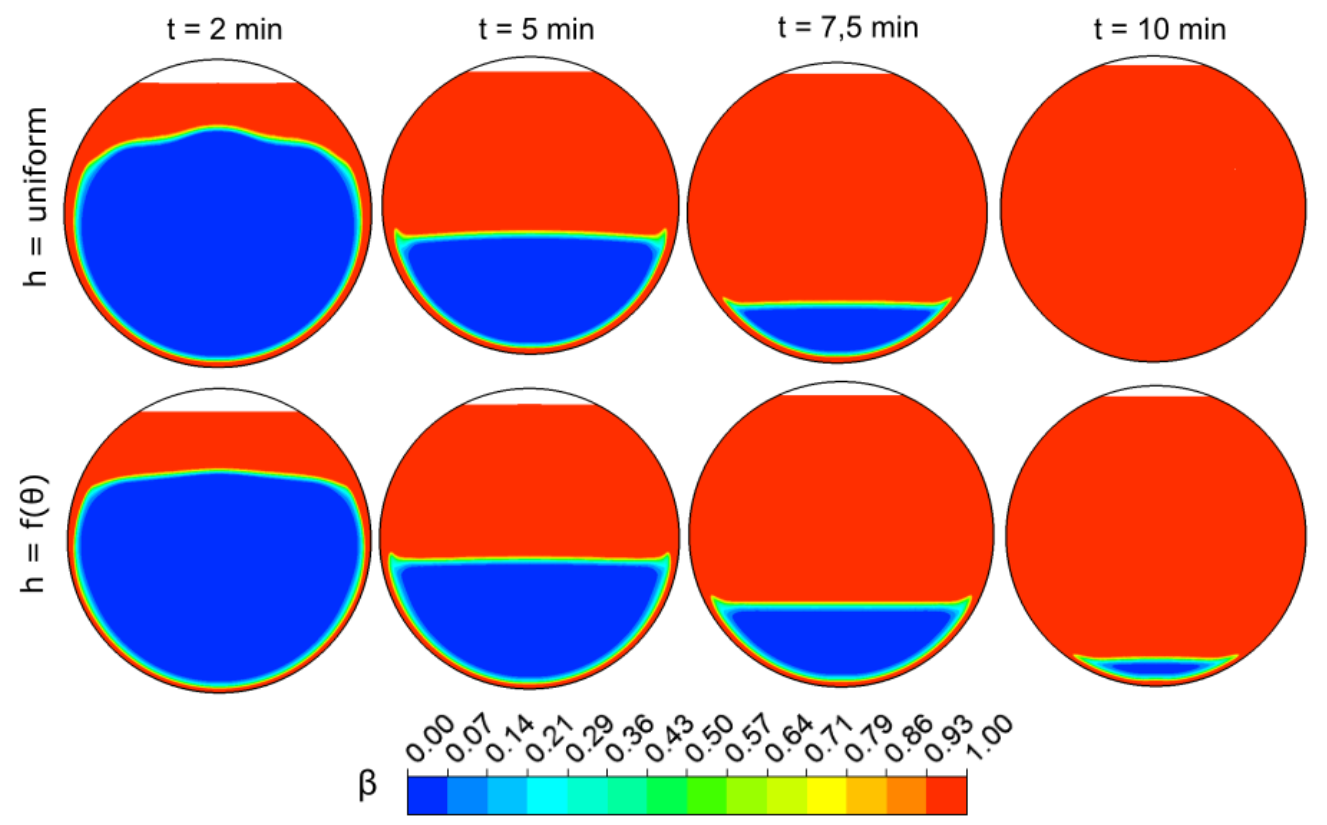

Figure 13 - Liquid fraction fields for, Position $1, \Delta \mathrm{T}=15 \mathrm{~K}, \mathrm{Re}=2.6 \times 10^{4}$, $\mathrm{h}_{\text {ext }}$ uniform and non-uniform, at: (a) $\mathrm{t}=2 \mathrm{~min}$; (b) $\mathrm{t}=5 \mathrm{~min}$; (c) $\mathrm{t}=7.5 \mathrm{~min}$ and (d) $\mathrm{t}=10 \mathrm{~min}$.

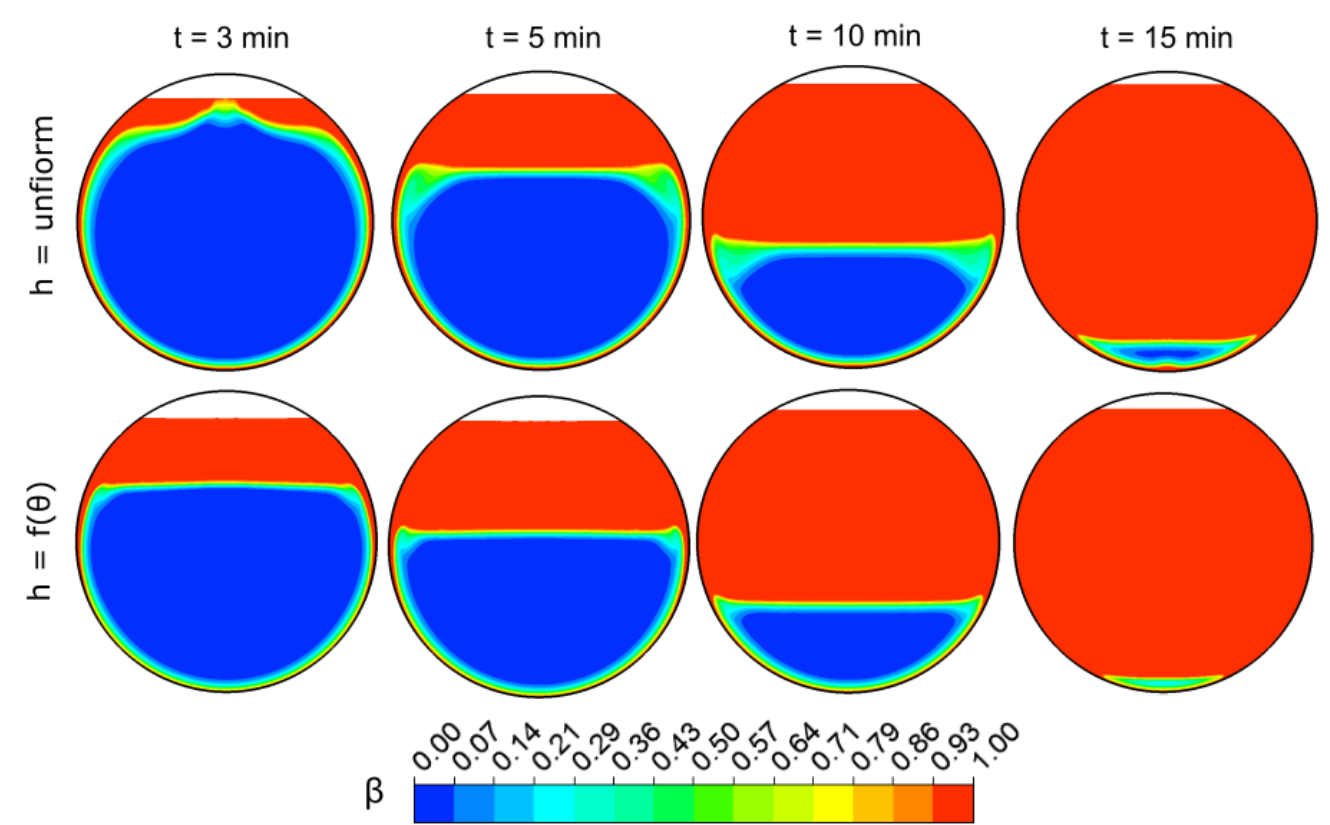

Figure 14 - Liquid fraction fields for: Position $1, \Delta \mathrm{T}=15 \mathrm{~K}, \mathrm{Re}=1.0 \times 10^{4}, \mathrm{~h}_{\mathrm{ext}}$ uniform and non-uniform, at: (a) $\mathrm{t}=2 \mathrm{~min}$; (b) $\mathrm{t}=5 \mathrm{~min}$; (c) $\mathrm{t}=7.5 \mathrm{~min}$ and (d) $\mathrm{t}=10 \mathrm{~min}$. 